secure the future of psychiatry we need to ensure that we attract the best candidates for training posts, and as such, studies into recruitment will need to continue.

1 Korszun A, Dharmaindra N, Koravangattu V, Bhui K. Teaching medical students and recruitment to psychiatry: attitudes of psychiatric clinicians, academics and trainees. Psychiatrist 2011; 35: 350-3.

2 Royal College of Psychiatrists. Psychiatry National Recruitment 2011: CT1 Outcomes. Royal College of Psychiatrists, 2011 (http:// www.rcpsych.ac.uk/pdf/CT1\%20recruitment\%200utcomes03.08.2011.pdf)

3 Scottish Medical Training. Competition Ratios 2009-2010. Scottish Medical Training, 2010 (http://www.scotmt.scot.nhs.uk/media/27625/ smt\%20website\%20competition\%20ratios\%202009_2010.pdf).

4 Welch J, Bridge C, Firth D, Forrest A. Improving psychiatry training in the Foundation Programme. Psychiatrist 2011; 35: 389-93.

5 Brockington IF, Mumford DB. Recruitment into psychiatry. Br J Psychiatry 2002; 180: 307-12

Rajesh Sekhri, ST5, Old Age Psychiatry, Leverndale Hospital, Glasgow, UK, email: rajeshsekhri@nhs.net, Ruth Sibbett, CT1 Psychiatry, Leverndale Hosptial, Glasgow.

doi: $10.1192 / \mathrm{pb} .36 .3 .118$

\section{Knowledge of mental health legislation in junior doctors training in psychiatry}

We read with interest the study by Wadoo et al focusing on the knowledge of mental health legislation in junior doctors training in psychiatry. As rightly stated by the authors, this is a concerning issue due to the possibility of inappropriate use of legislation that could potentially threaten patients' fundamental rights.

We would like to highlight a couple of issues which are concerning. We felt that doctors' knowledge of various aspects of the Mental Health Act will increase after they become Section 12(2) approved and attend the mandatory training. We feel that most of the sections of the Act are only used by doctors after they are Section 12(2) approved; however, there are certain aspects of the law which apply before the approval. These are mostly used in emergencies, when junior doctors are often the first port of call, often outside working hours when the support from senior and more experienced staff might not be as readily available.

We were anxious at the lack of knowledge of Section 5(2), where $65 \%$ of the trainees felt that they needed to examine the patient and $60 \%$ knew about the requirement to fill out a form.

We feel that junior doctors in training are frequently called to prescribe medications for agitated or disturbed patients. In the current study the trainees' knowledge about the consent to treatment fell to $20 \%$ (statement in the study is: 'after 3 months, second opinion must be obtained if the patient does not consent'). It can be concluded that the doctor may not be aware whether the patient's current consent to treatment form (T2) or a second opinion (T3) is covering the emergency medication. There is a risk a patient may be prescribed medication without consent and without the legal paperwork completed. We felt that such scenarios, apart from damaging the therapeutic relationship, could possibly lead to complaints or litigation against individual staff or the managing trust.

Although it is reassuring that experience results in improved knowledge of the legislation, we agree that training in mental health law and its clinical implications should be emphasised at an earlier stage in the junior doctors' career. Regular testing of competencies, as set out in the Royal College of Psychiatrists' curriculum, should follow attendance at mandatory formal training at induction and refresher courses.

1 Wadoo O, Shah AJ, Jehaanandan N, Agarwal M, Laing M, Kinderman P. Knowledge of mental health legislation in junior doctors training in psychiatry. Psychiatrist 2011; 35: 460-6.

Pratish B. Thakkar, Consultant Forensic Psychiatrist, Tees, Esk and Wear Valleys NHS Foundation Trust, Ridgeway, Roseberry Park, Middlesborough, UK, email: pratish.thakkar@tewv.nhs.uk, DeepakTokas, ST4 Forensic Psychiatry, London Deanery, Kent and Medway NHS and Social Care Partnership Trust, UK.

doi: 10.1192/pb.36.3.119

\section{Feelings of shame in a community psychotherapy group}

Crossley \& Jones' article on shame and acute psychiatric in-patient care ${ }^{1}$ was of great interest as the themes discussed are pertinent to the psychodynamic group we facilitate in a community rehabilitation service (an open group for patients with psychosis). The patients frequently bring up shame about their illness in different ways. The superordinate themes they identified are persistent themes within our group.

Patients talk about feeling looked at 'differently' by the public when on the streets or using public transport. They question this, wondering whether people can tell that they have a mental illness or whether they are paranoid. Avoiding potential feelings of shame has led to self-isolation and loss of independence for several of our patients.

Patients describe their 'loss of adulthood' and autonomy, especially when admitted to hospital. Their accounts of being cared for by mental health services are full of shameful experiences, such as being restrained. They notice the distance between their current position and a potential future 'adulthood', leading to feelings of hope and loss.

Issues regarding medication have obviously featured, including the pride felt in taking the responsibility of selfmedicating. They reflect on the stress of taking responsibility against the rewards of achieving goals. Our patients are undoubtedly being observed which, as stated in the paper, inevitably heightens feelings of self-consciousness. The group is able to voice these feelings when considering why they choose not to express opinions on certain topics. They have acknowledged feeling observed by other group members, as well as the facilitators, and the worry about being judged.

The group is developing increased self-worth and protesting against shameful feelings by expressing their concerns. There is compassion in the group for one another and a wish to increase each other's feelings of worth. Patients emphatically and movingly encouraged another physically immobilised patient to keep trying to 'recover'. They stated that it would be painful and he may cry but that he should not be ashamed of it and he would not be judged by them.

The paper helped us to consider the shame we may feel as group facilitators, especially when the group is curious about our lives. Envy of our idealised lives, in and out of work, has been present in the group. We feel guilt about how much 